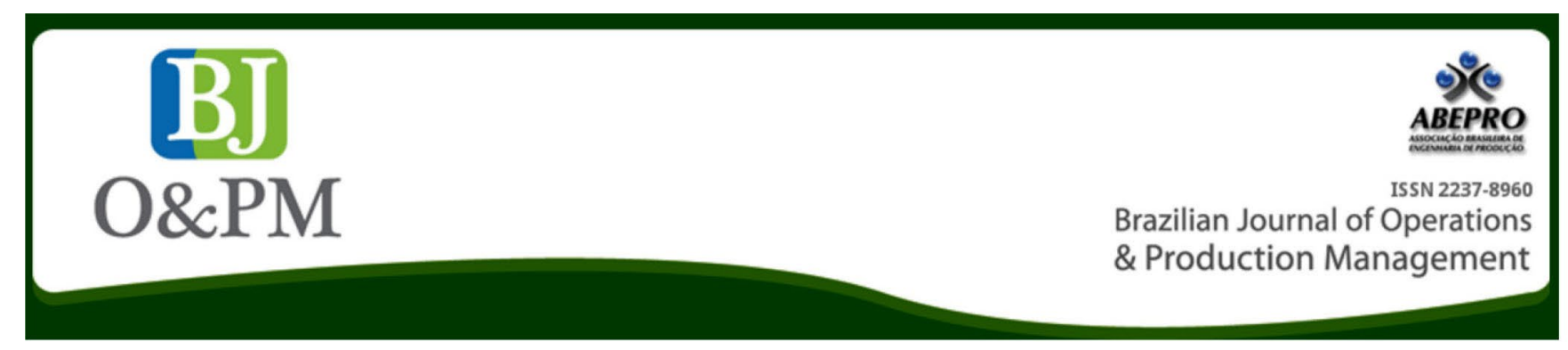

\title{
POTENTIAL USE OF BIM FOR AUTOMATED UPDATING OF BUILDING MATERIALS VALUES
}

Claudio Alcides Jacoski claudio@unochapeco.edu.br Communitarian University of Chapecó Region - Unochapecó, Chapecó, Santa Catarina, Brazil.

\section{Lissandro Machado} Hoffmeister

lissandro@unochapeco.edu.br Communitarian University of Chapecó Region - Unochapecó, Chapecó, Santa Catarina, Brazil.

\begin{abstract}
This study proposes an artifact motivated by improved assertiveness in building design budgets. Building Information Modeling (BIM), with the structure of the parametric objects created in a file format with the Industry Foundation Classes (IFC) extension, can provide the data for the object, facilitating the design's control and monitoring process. Through the adoption of the IFC standard in the creation of these objects, the exchange of information between the tools of different software providers becomes viable, allowing interoperability between systems. This is a desired situation in the construction industry, which incurs significant losses due to this problem. An important condition that can significantly contribute to the update of the information of the objects and the budget process is the incorporation of the possibility of updating the value information (price) of the BIM objects that are shared in repositories (object libraries). In this context, this study presents an alternative to updating and retrieving the values of BIM objects based on the IFC standard. An artifact (web environment) was produced linked to a model to meet the proposed objective. This method is presented by computing services, enabling the automated retrieval of the object value between the owners, the price repository and also the designers. The performed tests reveal the practicality of its implementation, with no extensive knowledge of the IFC structure being necessary. It suffices to simply follow the fill out pattern of the custom properties in IFC, defined during the creation of the object. The submission of the construction design to the repository allows for the retrieval of the values and the quantification of objects present in the design. This process is carried out in a simple manner, maintaining the synchrony and traceability of the object with the designer and the owners of the objects making up the architectural and complementary design.
\end{abstract}

Keywords: BIM; Building materials; IFC; automation. 


\section{INTRODUCTION}

The use of the IFC standard enables communication between the tools of different software providers, therefore allowing for perfect interoperability. This is a desired situation in the construction industry, which incurs significant losses due to this problem. One of the characteristics of using BIM is the sharing of information, a possibility that starts to become interesting when suppliers offer detailed conditions about their products, which remain linked to the designs throughout the life cycle process. Based on this, several libraries (repositories) were created, containing objects with a set of encapsulated information.

Today, however, designers have a limited access to objects, almost always offered by major manufacturers, who offer objects in BIM for their products and also generic objects that are offered through plugins for established software on the market. These objects are available in some virtual libraries (repositories) or are part of the package of the employed design tool. The values of these objects are usually reported as a reference value to support the budgeting stage and all updates must compulsorily be done by the designer.

An important condition that can significantly contribute to the update of the information of the objects is the incorporation of a possibility of updating the value information (price) of the BIM objects that are available in most of these repositories (object libraries).

According to a study conducted by Sakamori (2015), how the update of the database regarding object costs is performed, is not known. It's therefore a condition to be resolved, since the prices of inputs go through constant updates.

This proposal presents an artifact guided by computing services supporting the exchange of information between the designer and the owner of BIM/IFC objects, permitting the retrieval, update and insertion of the updated values of these objects based on their IFC structure.

\section{INTEROPERABILITY BASED ON THE IFC STANDARD}

The collaboration process using Building Information Modeling (BIM) is changing the way design data is being organized and the involved working methods. Cross-functional design teams use BIM software solutions to create intelligent digital 3D models. These models provide more visibility of the project to all those involved and increase the ability to make faster and more consistent decisions. BIM models are complementing (and may one day replace) construction documents as a new standard for sharing and delivering building design data.

Industry Foundation Classes (IFC) is an important standard for the exchange of data and information in the construction sector. The IFC data model contains both the geometry and the properties of "intelligent" construction elements and their relations with other elements in a building (central concepts of the BIM model). This allows for the transfer of these models and 3D modeling software information from one application to another, making collaborative work flows easier (Eastman et al., 2014).

The IFC standard is developed and maintained by BuildingSmart International, formerly known as the International Alliance for Interoperability or IAI, a nonprofit organization led by the construction industry.

As such, the IFC is a neutral and independent standard for the software from any specific provider.

Its standardization of class structures allows distinct applications, approved by the IFC standard, to read, operate and share information, ensuring a so-called interoperable standard. These extensions are public and open for use and implementation; they are defined by the industry, extensible and developed at any time as needed. The IFC is a central, object-oriented model with immediate interference in four initial areas: Architecture, Construction Services, Construction Work Management and Management Tools (Building Smart International, 2014).

\section{A NEW MOMENT WITH THE EVOLUTION OF BIM - BUILDING INFORMATION MODELING}

BIM presents itself as a methodology for the development and management of Architecture, Engineering and Construction (AEC) projects. The use of the BIM methodology in AEC seeks to increase the productivity, efficiency and quality of construction, and simultaneously to reduce costs throughout the life cycle of the ventures (Patacas, 2012). For Eastman et al. (2014), BIM is defined as a modeling technology and an associated set of processes to produce, communicate and analyze construction models.

Succar (2009) states that the full adoption of the BIM paradigm in the construction industry does not occur immediately. There are various stages of BIM adoption, with the gradual appropriation of the technology and transformation of the related processes, leading up to the full adoption of BIM.

BIM presents itself as a new way of exchanging information related to the design. This exchange involves various actors, professionals linked to AEC involved in the 
entire life cycle of the project, from the very start. According to Kiviniemi (2013), BIM does not have a single goal in a construction project. Instead, it's a methodology that seeks to serve multiple goals throughout the development cycle of the project. Depending on the target of each actor involved in the AEC project, the methodology can be used in different ways.

According to Fabrício (2002), design is a process in which information is created and handled by different forms of thinking, involving all the senses, abstractions, representations, craftsmanship, diagrams, algorithms and methods of knowledge. A building design can be summarized as a known process, which transforms and creates information, mediated by a series of human faculties, whether this is knowledge or certain techniques. It's geared toward the design of objects and also the formulation of solutions in order to anticipate a product and its operation.

A BIM model can include individual 3D models of each building component with all the associated properties, such as geometry, spatial relationships, information about material properties, product codes, materials used, their thermal properties, manufacturer names, etc. In addition to the information of the object, BIM also includes external associations between the construction components. Thus, when designing, all necessary information to validate is available in each of its elements (Li et al., 2014).

The modeling of information (BIM) is one of the most promising methods in architecture, engineering and construction (AEC). With the BIM technology, a virtual model of a building is fully built. This methodology, known as a digital model of building information, can be used for the planning, design, construction, as well as the maintenance of the facility. With the virtual model, it is possible for the AEC professional to visualize what will be built in a simulated environment. He'll be able to identify any potential conflict or operational problem, in addition to obtaining greater assertiveness in budgets. BIM represents a new paradigm in AEC that stimulates the integration of the functions of all stakeholders in a project (Azhar, 2011).

The importance of having a more suitable and more complex representation model, where all information is interconnected and synchronized, makes the implementation stage become safer. The design phases are arranged in a rational structure, divided by specialty, and stratified by level of detail (Jacoski et Jacoski, 2014).

\section{PREPARING THE VALUE UPDATE METHOD}

The performed case study proposes the establishment of an interoperable artifact to update BIM object values.
The method is constituted by the use of two main actors: firstly, the owner of the BIM/IFC object and, secondly, the designer who will use the BIM/IFC objects in his designs.

The basic sequence of the method's activities is primarily to allow the owner of the BIM/IFC objects to load the objects he owns.

Industry Foundation Classes (IFC) is the main construction product data model. It supports all designs and the entire construction life cycle and, according to Eastman et al. (2014), they are likely to become the international standard for data exchange and integration in the building construction industry. The IfcRoot class is a more basic and abstract class of the IFC model. It's the superclass of all the core layer entities (Kernel) and of all the other layers that make up the IFC scheme (Building Smart International, 2014)

The IfcRoot attributes a global and unique identifier to its subclasses, in addition to other ancillary information. This attribute is identified as Globalld, also known as Globally Unique Identifier (GUID) or Universal Unique Identifier (UUID).

Globalld consists of a sequence of 22 alphanumeric characters. It is generated by an algorithm that ensures this sequence is unique across the entire software universe (Building Smart International, 2014).

Despite the fact that Globalld is a unique and universal identifier, it was designed in such a way as to meet the proposal for the interoperable IFC standard. As explained above, the IFC data model contains both the geometry and the properties of "intelligent" construction elements and their relations with other elements in a building. As soon as these properties are changed for the object, the BIM tools understand that it is another object with other relationships and create a new Globalld identifier.

For this condition to be certified, first an object was inserted into a design in the ArchiCAD software according to Figure 1 . The test case used the armchair object, which was taken from a public repository with BIM modeling support. The main objective of this test was to validate the structure of information of its classes and the possibility of using the unique identifier called Globalld as a means of traceability.

By manipulating the object "armchair" through the IFC property manager in the ArchiCAD software, it was identified that the structure of information presented had the "Globalld -> 2XzE9LzWkbJfTx3NDOpU_J". 
Brazilian Journal of Operations \& Production Management

Volume 15, Número 1, 2018, pp. 35-43

DOI: 10.14488/BJOPM.2018.v15.n1.a4

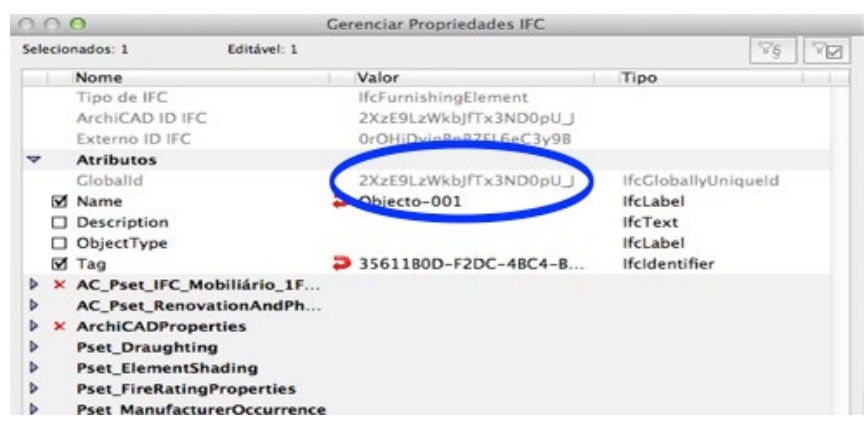

Figure 1. GlobalID of the armchair object

Source: Developed by the authors

After duplicating the object through a simple copy and paste operation that didn't alter the IFC properties or relations, it was manipulated to identify the GlobalID. Through the IFC property manager of the ArchiCAD software, the information structure revealed that a new "GloballD -> 36c4v1USsxJxQHsjkJniTD" was generated for the second object, since the original object had the following identifier "GlobalID-> 2XzE9LzWkbJfTx3ND0pU_J"

According to Graphisoft's technical documentation for the ArchiCAD tool (2015), which ratifies the test conducted for this study, this basically means that only the process of opening the file will keep the original GlobalID. If the file is saved in PLN (ArchiCAD file), however, the tool will change the GlobalID values to protect the elements in the original design.

\subsection{Validation of the Unique GlobalID and the Detected Problem}

According to Building Smart International (2014), IfcPropertySet is a container class that maintains a set of properties in the format of a hierarchical tree.

There may be thousands of different components being used in the construction of a building, and not all of them have a predefined class in the IFC model. The IfCPropertySet class can solve this problem, providing IFC's extendibility.

IFC addresses the property sets, or P-Sets. These are properties that are used together to define materials, performance, contextual properties, material behavior, etc. The $P$-sets have collections for various types of construction objects, but there are some specialized functions or properties. Options are available for these cases to define and represent the set of properties that can be customized by the user (Eastman et al., 2014).

IfcPropertySet instances are used to assign sets of named individual properties. Some property sets have instructions on how to assign meaningful, already predefined names, which are listed under "property sets".
The naming convention "Pset_Xxx" applies to the property sets and should be used as the value for the attribute "Name" (Building Smart International, 2014).

Before the performed test, it was concluded that the GlobalID identifier cannot be used for the proposed traceability of objects. This key must serve as a kind of object identity, i.e. it must track the object after its distribution. The original GlobalID may undergo changes. As such, the object would not be found if subjected to a search. This means that the object reference to the artifact is lost and that upgrade possibilities and the synchronization of values for the objects are not possible.

\subsection{Solution for the Unique Identifier through the Named Properties}

Based on the preceding definitions, a new test was executed with the creation of custom properties for the object "armchair". The definition of the properties was once again performed with the ArchiCAD tool. The tool has the following option: "Create a new IFC/classification property." Once the option to create a new custom IFC property is chosen, you are requested to fill out the property set's name.

Then the name of the property is requested. As such, a "key" was created and the type of the selected property was selected as "unique" because it is an identifier for the object. Finally, the selected type of value was set as "ifclabel". Based on the creation of the properties, the test presented in the previous section was executed again, using the first object with the identifier GlobalID-> 2XzE9LzWkbJfTx3ND0pU_J" as a starting point and submitting it to a new duplication by creating a third object in the ArchiCAD design.

By analyzing the IFC properties of the third object, one can see that, just as in the test presented in the previous subsection, the GlobalID is modified, since the original object kept the GlobalID-> 2XzE9LzWkbJfTx3ND0pU_J and the third object generated a new GlobalID-> 0sBaKcB2lhI9NJsrWJUcqt".

The ownership structure "Pset_Xxx", however, is maintained as in the original object. This validates the creation of the structure proposed by the "Psets", which ensures the object reference to the proposed artifact.

\section{DEVELOPMENT OF THE INTEROPERABLE ARTIFACT}

The method used was based on the definition of logic for the construction of the problem classes, i.e. the surveying of the practical problem found, targeting the search for an artificial instrument to obtain the searched result. 


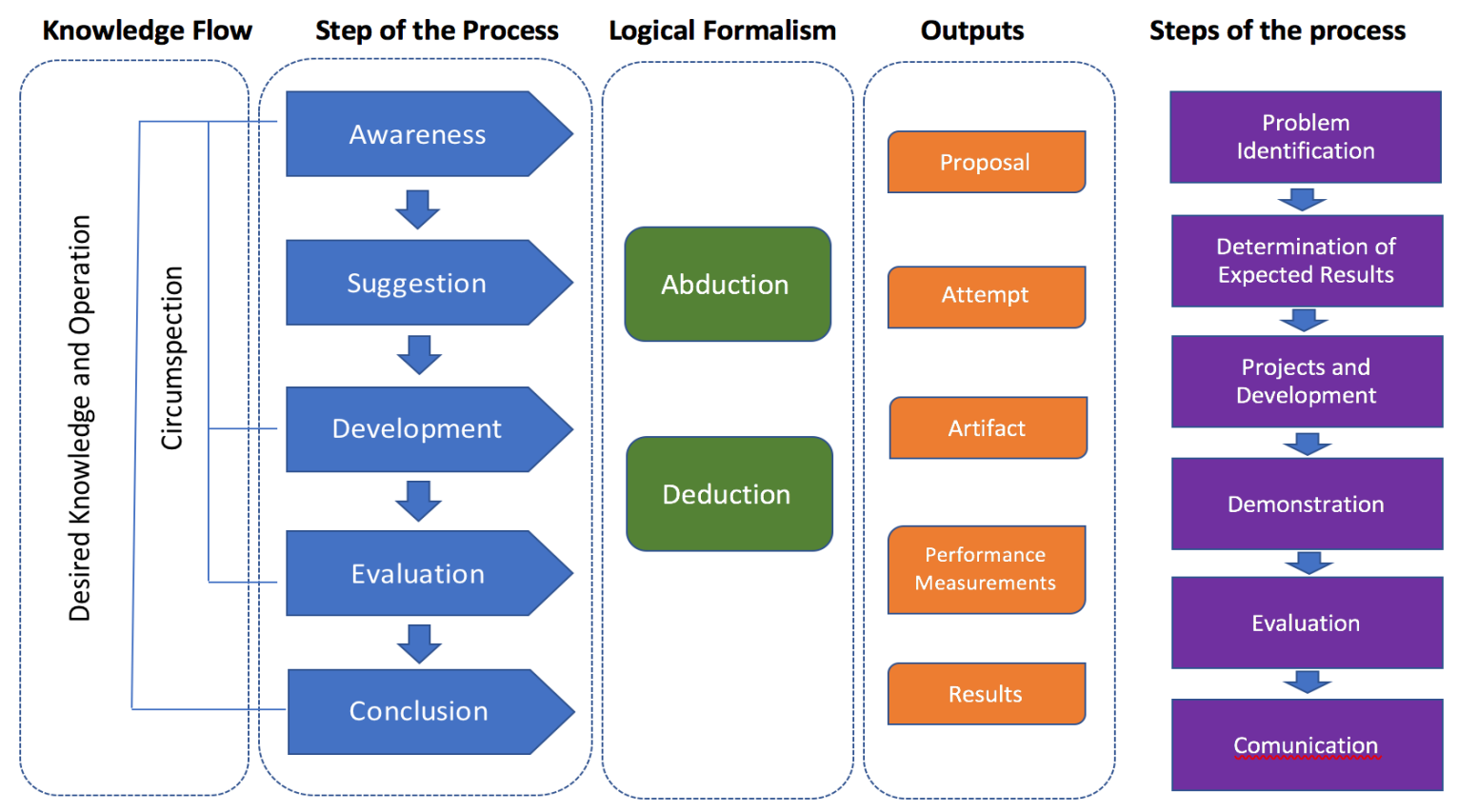

Figure 2. DSR Management Schematic

Source: adapted from Takeda et al., (1990); Vaishnavi et Kuechler (2004); Manson (2006); Peffers et al. (2008); Lacerda et al. (2013).

This artifact is presented in a prototype of an object repository based on a research model that follows the precepts of Design Science Research.

Design Science Research (DSR) is a new perspective or a set of analytical techniques that allow for the development of research in various fields. It seeks to study, research and investigate the artificial and behavior, both from an academic and an organization's point of view (Bayazit, 2004).

The artifact is the organization of the components of the internal environment to achieve a particular objective in the external environment (Simon, 1996). The proposed development of this study follows the study presented by Larcerda et al. (2013), represented by Figure 2 .

Initially, a survey was conducted to identify BIM object repositories so as to observe the current state of development of these repositories, in order to support the structuring of a model of an artifact that had as its main feature the updating of BIM/IFC object values.

The business model flow was then built to simulate the resources that would be served by the model and the services that would be required for the operation of the proposed method. Based on this flow, the identification phase of the requirements that could meet the proposed update and synchronization of object values was reached.
After the study of the IFC structure and defined requirements, the business model was validated. Finally, the testing phase was reached, validating the proposed method for the artifact, simulating all stages, ending with the submission of designs, with the return of the list of found objects.

\section{OBTAINED RESULTS}

The artifact is presented in a standardized and custom information structure defined by the IFC class for object creation. This method is presented by a system developed by computer algorithms. One of these algorithms is responsible for controlling and generating unique keys. A key is linked to an owner, who assigns it to an object.

The naming convention "Pset_Xxx" applies to the property sets and should be used as the value for the attribute "Name" (Building Smart International, 2014). The name of the property is then created, so "key" was created. In its structural properties, four additional properties were created within the set. One was called "Description", which served as a brief description of the object. Another was "Manufacturer", which must inform the name of the manufacturer or owner of the object. The property "Name" served to identify the object and, finally, there is the property "Price". The artifact is presented in the format of a repository model, designed for a computing environment, 
planned for the use by building designers and object owners. It offers some accessible web services through a credential and password to the creator of BIM objects. This credential has two access profiles, one as object owner and the other as designer.

This unique access credential not only identifies the user profile, but also ensures that only the holder of this credential may access certain services. One of these services is the registration (publication), posting or update of the object value, enabling consultations and future updates.

The registration of the object is one of the key features. Its registration was planned to be carried out automatically without the need to fill out information. For the registration of a new BIM/IFC object, a function was developed that performs the import and validation of the object. Figure 3 shows a simplified flow diagram model with the functions developed for the registration of a BIM/IFC object.

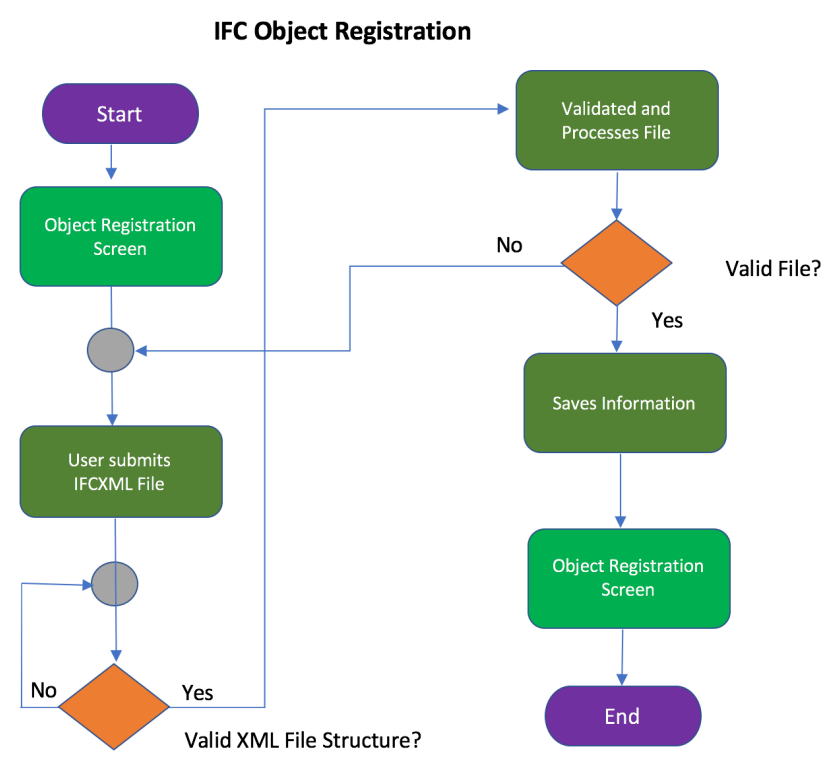

Figure 3. Flow registration IFC objects

Source: Developed by the authors

In order to make the update of object values more flexible and dynamic, WebService was made available. With this feature, the object owner user can develop integration routines with the ERP (Enterprise Resource Planning) system that manages all the daily operations of this company, assuming that most owners of the objects available in the value repository keep a register of objects in their legacy systems and a value in their database.

The service, called "changePriceObject", is accessed through a URL and some parameters need to be informed during the request. One of these parameters must be given in the request header. Its name is "Authorization" and its content must be the "owner access authorization." Two more parameters are required, one of them is the objects[hash], which is nothing more than the key object, and the other is the objects[price], which should be filled out with the value to be assigned to the object. The flowchart of this WS is shown in Figure 4.

The object receives value updates from its owner, and the value is stored in an information database.

When the object owner performs the value update, a procedure identifies which designers submitted their designs to recover values and communicate them.

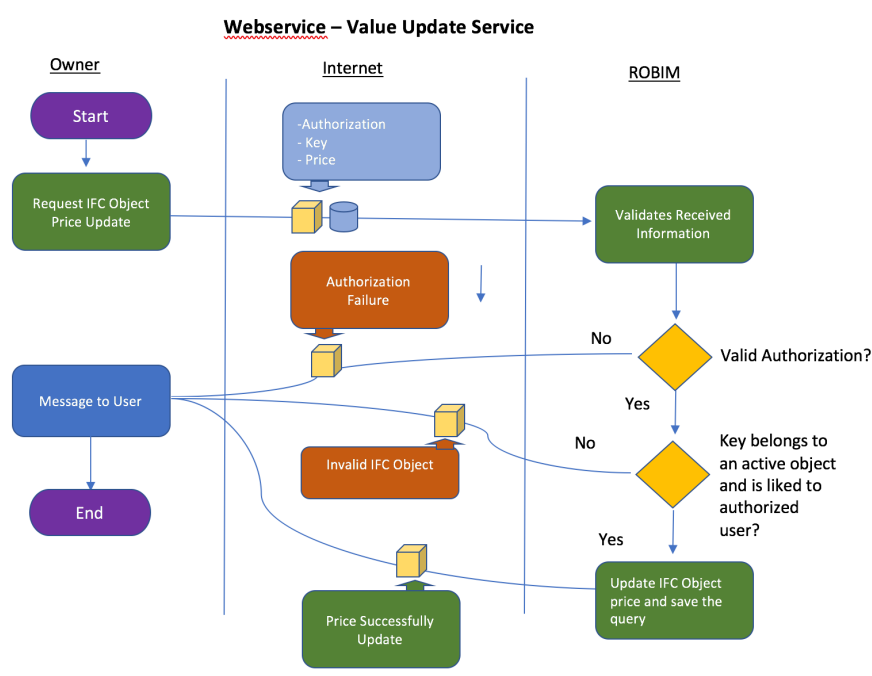

Figure 4. Object Price Update Service

Source: Developed by the authors

The IFC object is distributed and carries a key within its class structure. Once the design is submitted, the method identifies the objects and quantifies them. Subsequently, the value of the object is retrieved, and it is stored in a database along with the date the owner of the object updated it.

When the design is submitted, it will return the updated information of its price to the designer. For the execution of the test, the registered object containing the key "c09ca71ea73fccb5dfb0a486cc3b9335" was used. Once this object was included in the design, two more copies were produced as in Figure 5.

The method manages a communication between agents by retrieving values at the time the design is submitted. The object owner receives a communication that the object is being used in a design, and the value information that is stored in the database. This flow is shown in Figure 6. 


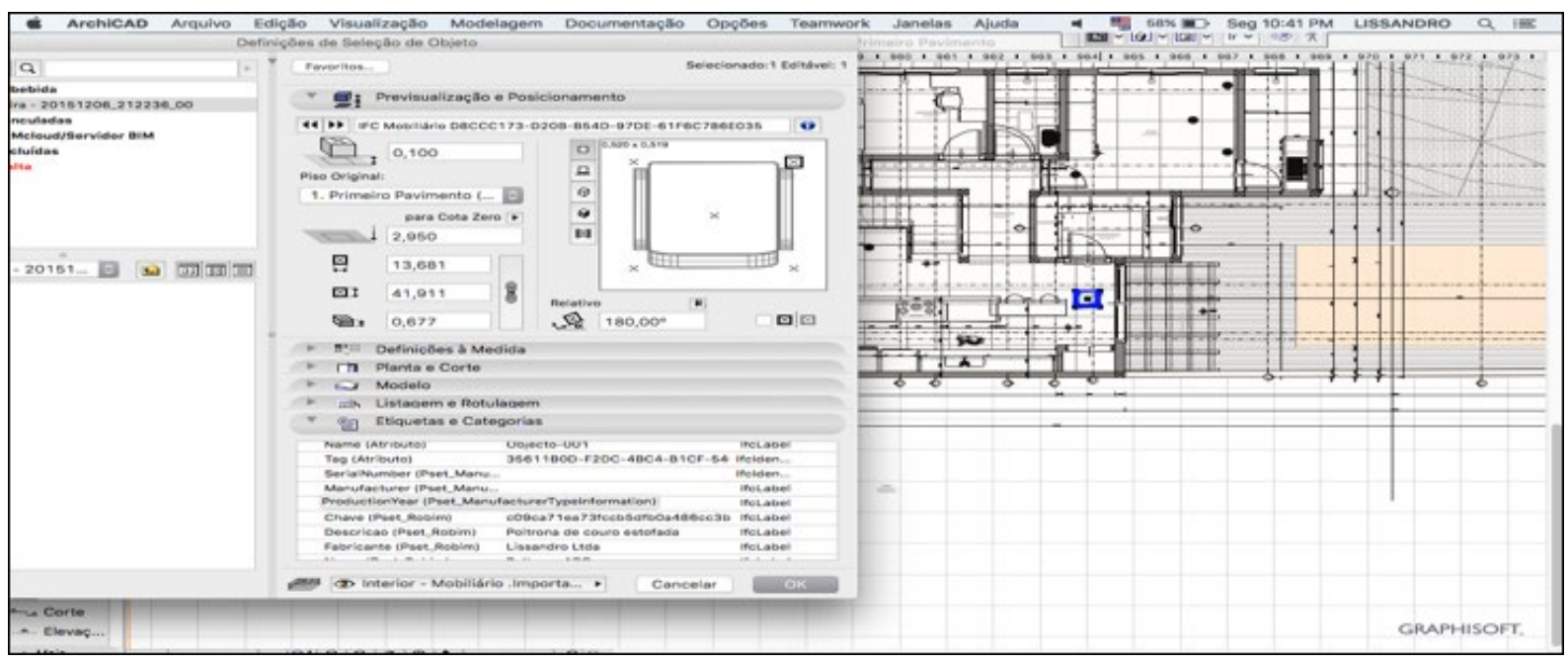

Figure 5. BIM design submitted to the artifact

Source: Developed by the authors

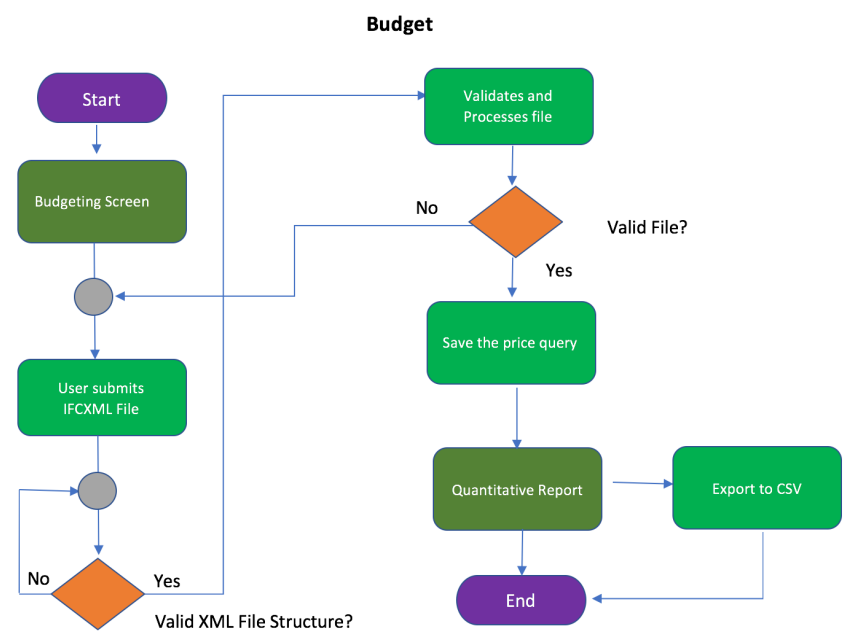

Figure 6. Flow generating amounts and budgets Source: Developed by the authors

Once all checks have been performed and the file validated, the artifact shows all the objects that were found in the design that is registered in the repository as a result.

Objects with the same key are grouped and quantified. The artifact queries the repository that returns the price information updated by the object owner. As shown in Figure 7, the object "Armchair ABC", containing the key "c09ca71ea73fccb5dfb0a486cc3b9335", was located and the amount of 3 units was presented, in addition to the other objects included in the design.

As such, a spreadsheet with amounts and a summary of values based on the budgeting was obtained.

\section{CONCLUDING REMARKS}

This study presents a proposal for the updating and retrieving of the values of BIM objects based on the IFC standard. The artifact's name was given by the presented proposal, where owners of objects offer and maintain an information database with updated values of objects that can be consulted by designers.

These objects are distributed and embedded to designs. The designs submitted to the repository return amounts and updated values to support budgeting.

The performed tests reveal the practicality of its implementation, and no extensive knowledge of the IFC structure is necessary. It suffices to simply follow the fill pattern of the custom properties in IFC, defined during the creation of the object. The submission of the construction project to the repository allows for the retrieval of the values and the quantification of objects present in the project.

The artifact was developed for access via the Internet without the need for software installation or resources on the PC of both the designer and the object owner. The proposal wasn't aimed at presenting a final software product, but rather the possibility to validate the flow that was proposed for the method. The resources developed by computer algorithms can be incorporated into existing repositories, or even improve their features for a final product.

Even during the development of this study, the difficulties in incorporating BIM with budget and quantitative management support could be observed, in addition to the extent to which existing solutions to recover values for BIM/IFC objects need to be improved. 


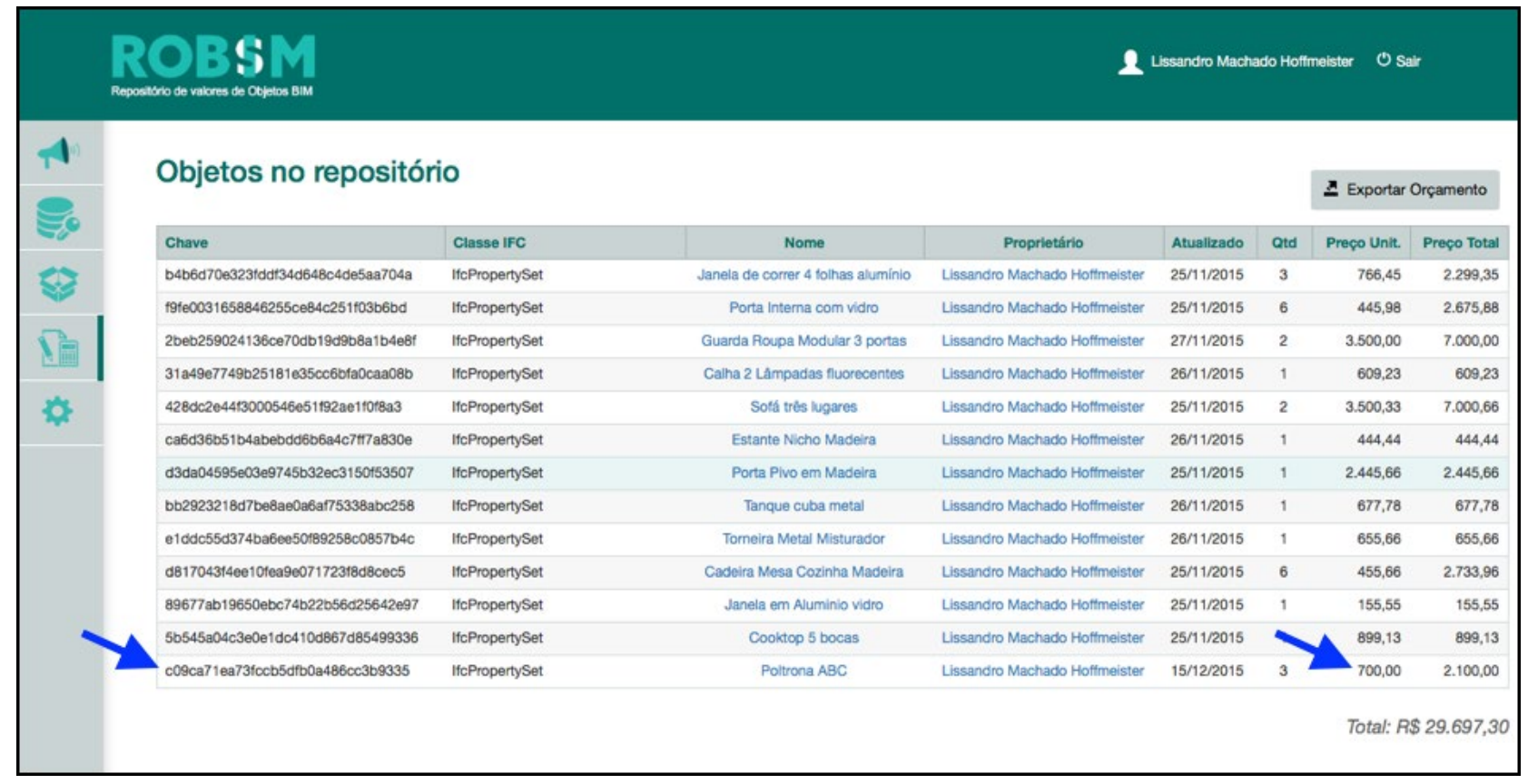

Figure 7. Object value spreadsheet

Source: Developed by the authors

This difficulty is evident when the value returned by some existing methods refers to a generic object, not taking into account different characteristics.

When the designer makes use of an object "door", for example, which is recovered from a repository, in some solutions, value reference tables of this door are used. Something that hinders budget assertiveness is the fact that this "door" object may have different characteristics, either because of the material used, size, etc., and so this reference value may be totally out of sync with the market value. If one imagines a design that makes use of great amounts of this "door" object, such as a hotel design, for example, then there is an even greater chance of budget errors.

\section{REFERENCES}

Azhar, S. (2011), "Building Information Modeling (BIM): Trends, Benefits, Risks, and Challenges for the AEC Industry, Leadership and Management in Engineering [s.I.]", Vol. 11, No. 3, p.241-52, available from: http://dx.doi.org/10.1061/ (asce)Im.1943-5630.0000127 (Access: 30 Jan 2018).

Bayazit, N. (2004), "Investigating Design: A Review of Forty Years of Design Research", Design Issues, Vol. 20, No. 1, pp. 16-29, available from: http://dx.doi. org/10.1162/074793604772933739 (Access: 30 Jan 2018).

Building Smart International Ltd. - BuildingSmart (2014), Institutional Website, "Model Support Group", available from: http://www.buildingsmart-tech.org. (Access: 30 Jan 2018).
Eastman, C. et al. (2014), Manual de BIM: Um guia de Modelagem da Informação da Construção para Arquitetos, Engenheiros, Gerentes, Construtores e Incorporadores, Bookman, Porto Alegre.

Fabricio, M. M. (2002), Projeto Simultâneo na Construção de Edifícios, Tese de Doutorado em Engenharia, Universidade de São Paulo, São Paulo, SP, 2002.

Graphisoft (2015), "Help Center - Import Functions", available from: https://helpcenter.graphisoft.com/guides/ archicad-20/archicad-20-reference-guide/interoperability/archicad_file_types_opened_by_archicad/file_types/importexport_settings/ (Access: 20 Feb. 2018).

Jacoski, C. A.; Jacoski, S. F. (2014), “Contribuição da Modelagem Bim para Projetos Complexos - Um Estudo com Projetos de Parques Tecnológicos", Gestão \& Tecnologia de Projetos [s.l.], Vol. 9, No. 1, pp.25-42, Universidade de São Paulo - Sistema Integrado de Bibliotecas - SIBiUSP, disponível em: http://dx.doi.org/10.11606/gtp.v9i1.69567 (acesso: 30 jan. 2018).

Kiviniemi, A. (2013), "Public clients as the driver for open BIM adoption-how and why UK government wants to change the construction industry?", Conference at Clareon Hotel Airlanda Airport, Open BIM, 2013.

Lacerda, D. et al. (2013), “Design Science Research: Método de Pesquisa para a Engenharia de Produção", Gestão \& Produção, Vol. 20, No.4, 741-61, disponível em: http://dx.doi. org/10.1590/S0104-530X2013005000014 (acesso em: 30 jan. 2018). 
Li, J. et al. (2014), "Benefits of Building Information Modelling in the Project Lifecycle: Construction Projects in Asia", International Journal of Advanced Robotic Systems [s.l.], pp.115, available from: http://dx.doi.org/10.5772/58447 (Access: 30 Jan 2018).

Manson, N. (2006), "Is operations research really research?", Orion, Vol. 22, No. 2, pp. 155-80, available from: http://dx.doi. org/10.5784/22-2-40 (Access: 30 Jan 2018)

Patacas, J. Luís M. L. (2012), Metodologia para suporte de processos colaborativos na indústria da construção baseada em interoperabilidade e BIM, Dissertação de Mestrado em Engenharia Civil, Faculdade de Ciências e Tecnologia Universidade Nova de Lisboa, Lisboa, 2012, pp.120.

Peffers, K. et al. (2008), "A Design Science Research Methodology for Information Systems Research", Journal of Management Information Systems, Vol. 24, No. 3, pp. 45-77, available from: http://dx.doi.org/10.2753/MIS0742-1222240302 (Access: ??).
Sakamori, M. M. (2015), Modelagem 5D(BIM) - Processo de orçamentação com estudo sobre controle de custos e valor agregado para empreendimentos de construção civil, Dissertação de Mestrado em Curso de Programa de Pós-graduação em Engenharia de Construção Civil, Universidade Federal do Paraná, Universidade Federal do Paraná, Curitiba, 2015, pp. 178.

Simon, H. A. (1996), The Sciences of the Artificial, 3rd ed., MIT Press, Cambridge.

Succar, B. (2009), "Building Information Modelling Framework: a research and delivery foundation for industry stakeholders", Automation in Construction, Vol. 18, No. 3, pp. 357-75.

Takeda, H. et al. (1990), “Modeling Design Process", Al Magazine, Vol. 11, No. 4, pp. 37-48.

Vaishnavi, V.; Kuechler, B. (2004), Design Research in Information Systems, last updated August 16, 2009, available from http://aisnet.org/?page=designresearchmethod\&terms=desi gn+and+research (Access: 30 Jan 2018)

Received: Sept 09, 2017

Approved: Jan 29, 2018

DOI: 10.14488/BJOPM.2018.v15.n1.a4

How to cite: Jacoski, C. A.; Hoffmeister, L. M. (2018), "Potential use of BIM for automated updating of building materials values", Brazilian Journal of Operations \& Production Management, Vol. 15, No. 1, pp. 35-43, available from: https://bjopm.emnuvens.com.br/bjopm/article/view/396 (access year month day). 